\title{
O corpo entre a ação e a contemplação na sociedadelaboratório \\ Rogério Moura*
}

Resumo: Os estudos do corpo prosseguem com grande relevância para a pesquisa contemporânea em educação e arte. Atravessado por uma miríade de referências teóricas e práticas, perfurado e transfigurado a partir de uma perturbadora combinação entre natureza, sociedade, ciência e tecnologia; mergulhado num campo de tensōes no qual se aproximam, se distanciam ou se sobrepôem conceitos e categorias como o sujeito, o objeto e a imagem, o corpo, que é mente incorporada e compreende um "observador livre" ao mesmo tempo, precisa ocupar um entrelugar a partir do qual seja possível resistir à perda de unidade, organicidade e integridade.

Palavras-chave: corpo; mente; objeto; ciência; educação; arte.

\section{The body between action and contemplation in the lab-society}

Abstract: Studies on the body have had continuous progress lately, with great relevance for the research in education and art. Crossed by a variety of theoretical and practical references, transformed by a disturbing combination of nature, society, science and technology, submerged in a field of tensions in which concepts and categories like subject, object and image keep close, take distance and overlap, the body, which is embodied mind and carries a 'free observer' at the same time, needs to occupy a between-place, from which it would be possible to resist to its lost of unity and integrity.

Key words: body; mind; object; science; education; art.

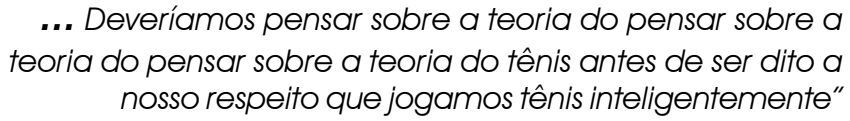

(Eric Matthews, 2007, p. 66)

\footnotetext{
* Professor do Departamento de Educação, Conhecimento, Linguagem e Arte (Delart) e pesquisador do Laboratório de Estudos sobre Arte, Corpo e Educação (Laborarte) da Faculdade de Educação da Unicamp, Campinas, SP, Brasil. rogermou@unicamp.br
} 


\section{Conceito e história}

Hoje, vários cientistas e pesquisadores produzem conhecimento, tendo como base os estudos do corpo. Isso tem ocorrido mais visivelmente em espaços que privilegiam o cérebro, embora o corpo possa e deva ser abordado de diferentes perspectivas, se forem levados em consideração campos tão diferentes como a medicina; a saúde; as artes corporais, cênicas, visuais; o esporte e a educação física.

Assim, a área de conhecimento determina, em maior ou menor grau, a forma de viver o corpo, pensar sobre ele e desenvolver reflexôes em torno do conceito, mas em todas elas, não se pode negar, há um ritual que torna os movimentos de alguma maneira homogêneos no corpo de quem escreve sobre o corpo: o esforço humano para transformar ideias e práticas corporais em texto segue mais ou menos a seguinte partitura de açōes físicas: sentar-se, procurar as anotaçôes, consultar dados e imagens, retomar anotaçôes e registros, organizar o pensamento e iniciar a escritura. Sem dúvida, este é um grande desafio para os que produzem e pensam a arte e transformam esse fazer e pensar em produto textual.

Nesse ritual, o indivíduo neutraliza quase todos os movimentos do corpo, que vão diminuindo à medida que a reflexão se aprofunda, até mergulhar no assunto de forma definitiva, para produzir o que costumamos chamar de conhecimento. $\mathrm{O}$ papel A-4, que em certa medida se torna um espaço de liberdade para o cérebro por meio dos pensamentos, passa a representar um espaço de fundo branco, uma espécie de pen-drive no qual as ideias e as práticas corporais de alguma maneira serão convertidas e de certa forma comprimidas.

Arendt (2007, p. 23) recorre aos estudos de Thomas de Aquino para falar desta cessação dos movimentos do corpo: "Todos os movimentos, os movimentos do corpo e da alma, bem como o discurso e o raciocínio, devem cessar diante da verdade".

Será essa a razão pela qual neutralizamos todos os movimentos do corpo para produzir conhecimento? Em nome da busca da verdade? Parece que, dentro dessa abordagem filosófica, esse encontro com a verdade exigiria de nós a neutralização de todos os movimentos, inclusive os da alma e os do cérebro.

Poder-se-ia inferir, então, que a ideia moderna de universidade possa ter estado baseada numa busca pela verdade (teoria), que teria levado à contemplação e, portanto, a toda cessação do movimento corporal como condição para produção do conhecimento. Será por isso que escolas e universidades são muito mais cerebrais do que corporais?

É curioso que Hannah Arendt, ao introduzir a discussão sobre os conceitos de vida ativa e contemplativa, recorra ao bios politikos, de Aristóteles, para ex- 
plicar os três modos de vida (bioi) que os homens poderiam escolher livremente no contexto grego: a vida voltada para os prazeres do corpo, a vida voltada para os assuntos da polis e a vida voltada para a investigação e a contemplação das coisas eternas. Qual dos três ou quais dos três modos de vida ainda podem ser exercidos exclusiva e/ou separadamente pelos humanos hoje?

No esforço de compreender os significados do corpo e o que a autora citada chamou de primado da contemplação sobre a atividade, há sempre o risco de tomar o corpo a priori como um objeto, como se verifica em práticas científicas que resultaram de grande e aparente hibridação de abordagens e áreas de conhecimento, levando a uma espécie de amálgama entre diversas disciplinas; porém, muitas vezes, restabelecendo uma separação relativamente clara, para fins específicos e úteis, entre sujeito e objeto. Refiro-me aqui, sobretudo, a um corpo que está postado diante da medicina, do poder absoluto do Deus Esculápio, no contexto de uma gestão dos corpos, dentro de um matrix que Moulin (2008, p. 15-82) chamou de sociedade-laboratório.

Por tratar-se de uma discussão desafiadora sobre um conceito que é complexo, poroso e problemático, é melhor já abordar de maneira mais didática algumas definiçôes da palavra corpo, entre as quais se encontram: "corporação", "corpo como tronco" e "corpo como conjunto" ou "unidade das partes". O texto explorará a ideia de unidade entre as partes, como integridade e organicidade, como abordagem principal para pensar o corpo na educação, na arte e, portanto, na ciência.

Ao abordar o que chama de gênese e migração das teorias do corpo, Greiner (2005, p. 15-48) destaca "que a palavra tem a raiz em KRP, de acordo com o dicionário indo-iraniano". Segundo sua interpretação, não haveria aí qualquer separação entre corpo vivo (Demas) ou morto (Soma), como se observa no contexto grego antigo, aspecto que ainda, segundo ela, poderia estar na base do que gerou a dicotomia entre material e mental. As letras "KRP", por sua vez, compõem também, no alemão moderno, a palavra corpo (Körper), embora também nessa língua encontremos duas formas de expressar o conceito de corpo (Körper/Leib), o que tem consequências filosóficas e epistemológicas importantes.

Em língua portuguesa, os desafios aparecem já a partir de uma simples consulta a dicionários eletrônicos sobre a palavra corpo, levando a inúmeros significados ou definições. ${ }^{1}$

I. Para conhecer os múltiplos significados da palavra "corpo", é possível consultar, por exemplo: $<$ www.priberam.pt>, digitando a palavra "corpo", para verificar as dezenas de palavras associadas ao conceito. 
Um olhar sobre as várias definiçôes permite destacar pelo menos quatro categorias relacionadas às definições da palavra: sociológica, material, fenomenológica e fisiológica.

Um dos aspectos centrais aí é a ideia de que um corpo se mantém como tal, na medida em que preserva a integridade de suas partes, embora, para manter a integridade, demande, em alguma medida, uma diferenciação, uma separação do meio, sendo esse meio (ambiente) um pano de fundo que permita a essa identidade, organicidade e integridade corporal manter-se coesa.

A possível dilatação do conceito de corpo, que é o todo e são as partes ao mesmo tempo, está presente na discussão conduzida por Fischer-Lichte (2000) em texto que chamou de "Dissolução das fronteiras do corpo", no qual discute a produção de calor corporal como condição para a catarse.

Nos últimos anos, exposiçōes como a de Gunther Von Hagens (Körper Welten), fazem-nos pensar em que medida ética e estética se misturaram, por exemplo, a partir do processo de plastinização industrializada de cadáveres inaugurado pelo médico alemão. Surge, então, um novo fato estético do encontro entre o corpo vivo, do espectador, e o corpo morto (o cadáver plastinizado), em exposição pelas galerias do mundo.

A partir destas primeiras considerações, é preciso admitir que, embora o conceito de corpo continue sendo intensamente tematizado e representado pela biologia e pela medicina - algo que se manifesta com veemência no fato visual e performático de sua plastinização, por exemplo —, constata-se uma hibridação de campos de conhecimento cada vez maior na prática e na teoria corporal, o que interferiria em aspectos como: coesão conceitual, clássica separação entre sujeito e objeto, limites da ética e da estética no processo perceptivo de leitura do corpo; e, sobretudo, recolocaria no centro das discussóes sobre a teoria corporal a ideia de oposição entre cessação do movimento corporal e atividade, como premissa para chegar à verdade.

$\mathrm{Na}$ arte da performance, os trabalhos tanto de Joseph Beuys quanto de Marina Abramovic são exemplos de novas perspectivas sobre o corpo que, ao ocorrerem num entrelugar entre a arte e a vida, entre a ética e a estética, propõem, em alguma medida, a sua reinvenção. A arte da performance possui enorme poder pedagógico, embora não manifesto, visível e didático como o ato de educar na sala de aula, permitindo-nos colocar em questão as fronteiras da ética e da estética, do intrincamento do bom e do belo na definição de corpo, extrapolando os limites impostos pela biologia.

No campo da educação, o que essas práticas corporais também demonstram é o quanto, em espaços como o edifício do teatro e da escola, a separação entre palco e plateia e entre professor e aluno tornou-se obsoleta para o enten- 
dimento de um corpo que reluta em manter-se retesado e extático diante do deus Esculápio (Deus da Medicina), como as estátuas pensantes de Norbert Elias, em sua obra $A$ sociedade dos individuos.

Tratar-se-ia da possível emergência de um sujeito pós-moderno, que acarretou uma crise da individualidade, apontada por Ghiraldelli (2007, p. 41-60), na qual o corpo, fragmentado e reconstruído a partir de amálgamas bio-tecnoestéticas, perdendo, portanto, seu sentido anterior de unidade, ganha uma hipervisualidade capaz de conceder a ele o papel de um eu-corpo, um eu que se converte em massa corporal?

Emana daí uma dúvida devastadora para o artista e para o professor, relacionada à escolha do conceito de corpo com o qual trabalhará, condicionada, por sua vez, pela oscilação entre coesão ou fragmentação, na qual o corpo estaria submerso.

A emergência do eu-corpo redefine fronteiras éticas e estéticas, enquanto as teorias corporais, que reivindicam ora uma abordagem mais ética, como na educação, ora uma abordagem mais estética para o corpo, como na arte, pressionam outros campos de conhecimento que têm no corpo a forma de manutenção de seu poder, visando outros rearranjos, no exercício de entendimento e tematização do conceito de corpo.

A educação, ou a Erziehungswissenschaft (ciência da educação), em alemão, foi pródiga em eleger o cérebro como seu arauto nos últimos séculos, pelo menos até certa insurreição desse corpo. A emergência deste, tematizado por Nietzsche como "a grande razão", representa uma forma de resistência ao domínio do cérebro, ainda que se reconheça que o conceito de eu-corpo seja polêmico e contraditório.

Uma forma objetiva de compreender o papel dessa emergência do eu-corpo é a pressão que se exerce sobre o campo da educação, a partir da enorme gama de atividades práticas ou corporais, esportivas, artísticas e de lazer que se alastraram pelos sistemas de ensino da educação básica e também nos espaços operados por Organizações da Sociedade Civil — OSC — ou ONG.

Por outro lado, a experiência de ser e ter um corpo, nesta ordem, como está postulada na obra de Merleau-Ponty (2006a, 2006b), requer que se possa, em primeiro lugar, compreender o significado de ser e observar-se como corpo, fundir-se com ele, mas, ao mesmo tempo, afastar-se dele para melhor compreendê-lo. $\mathrm{O}$ mestre francês, tido como relativista dialético, portanto, muito antes da supremacia das ciências do cérebro, ensinou-nos que a contradição entre ser e ter um corpo nasce com a nossa própria condição de humanidade; portanto, com o processo de consciência que nos permitiu desenvolver o trabalho, dominar a natureza e, assim, prolongar a idade do mundo pela cul- 
tura e pela memória. Nosso corpo é, portanto, no mímimo, resultado de uma luta eterna entre nossa porção homo faber e nossa porção animal laborans, conforme a terminologia utilizada por Hannah Arendt.

Essas preliminares tiveram o objetivo de demonstrar que escrever sobre o corpo é, no mínimo, uma multiatividade, que certamente requer um afastamento do objeto, o corpo, e que só pode ser parcial, porque escrever sobre o objeto corpo muda o próprio sentido que este possui para o sujeito ou indivíduo que quer tematizá-lo; o mesmo ocorre com o leitor de um texto sobre o corpo, este também enredado numa eternidade de ser e ter um corpo, um corpo aprisionado pelos processos de labor, mas capaz de estabelecer a eternidade do mundo pelo trabalho, pela intervenção da mão humana sobre a natureza.

Como homo faber, não há diferença entre o gari da rua, o malabarista do sinal de trânsito e o cientista professor-doutor que, na universidade pública, desenvolve nanorrobôs para combater doenças na corrente sanguínea.

A experiência de escrever conduz a um questionamento de por que os espaços de produção de conhecimento acadêmico e dos saberes escolares, a universidade e a escola, embora marcados pela presença, pelo movimento e pela visualidade corporal, sem os quais seriam somente grandes espaços de cimento, ferro e vidro abandonados, constituem-se em lugares que, em sua maior parte, privilegiam a passividade corporal, favorecendo o cérebro como um supraórgão que vem consagrar as tradicionais formas de pensamento, de construção do conhecimento e de reflexão ao longo dos séculos.

Parece que a universidade e a escola querem reafirmar a velha separação entre a carne e o verbo, cuja luta tenderia a ser vencida por ele contra ela, como apontou Gleise (2007, p. 1-21). Essa anatomia ao vivo como verbo totalitário ou essa prevalência do verbo sobre a carne, conforme referência feita pelo autor às escrituras do cristianismo, fazem refletir sobre alguns postulados cartesianos, como, por exemplo, o de que um corpo é extenso e não pensa e, por sua vez, é dominado por uma mente ou alma que, sem extensão, estabeleceria o seu domínio sobre ele.

Ao defender a ideia de corpo como "unidade entre as partes", pretendo sugerir um lócus, um lugar onde se vive e de onde se fala sobre ele, espécie de reunião entre corpo e mente. Um lugar que não é nem o de um corpo esfacelado e mutilado pelo pensamento cartesiano e mecanicista, mas também não é um lugar que celebra um triunfalismo do corpo sobre a mente, sobre o cérebro, sobre a palavra e sobre o verbo.

Nesse entrelugar do corpo na vida contemporânea, a ética e a estética estão num continuum, já que precisam servir a um ponto de equilíbrio entre a ação (a 
única coisa que se dá entre os homens sem a mediação da matéria, segundo o pensamento de Arendt) e a contemplação, este recuo necessário perante o mundo para refletir sobre ele, compreendê-lo, mas também para preservá-lo pelo trabalho e pela cultura. Isso quer dizer que a fronteira entre ética e estética se tornou liquefeita.

Do ponto de vista da abordagem histórica sobre o corpo, é inegável a contribuição de Corbin, Courtine e Vigarello (2008) que, além de realizarem um verdadeiro inventário da história do corpo desde a Idade Média, apontaram de forma consistente a evolução do conceito no século XX, no contexto do que chamaram de mutações do olhar.

Trata-se de obra que discute vigorosamente a invenção e a representação do corpo genético e suas consequências, mas também destaca a presença e a importância do corpo nos esportes, no cinema, na dança e nas artes visuais. Nessa obra, em especial os textos de Georges Vigarello sobre os esportes, o texto de Annie Suquet sobre o corpo dançante e, finalmente, o de Yves Michaud sobre as artes visuais, são de leitura obrigatória para estudiosos e pesquisadores do corpo.

\section{O trabalho de nossas mãos e o labor de nosso corpo}

Mas prosseguir com a discussão e a defesa da ideia de que o corpo está num entrelugar a partir do qual seria possível compreender a ação e a contemplação dentro de um continuum requer alusão a um importante conjunto de autores. Entre eles, destaco as discussões associadas ao campo do trabalho, especialmente o pensamento de Arendt (2007), que articulou num sistema os conceitos de trabalho, de labor e de ação.

Arendt (2008, p. 15-30) introduziu a discussão sobre o conceito de vida ativa, ao qual associou três outros importantes: o trabalho, o labor e a ação. Para essa autora, labor compreende "a atividade que corresponde ao processo biológico do corpo humano, cujos crescimento espontâneo, metabolismo e eventual declínio têm a ver com as necessidades vitais produzidas e introduzidas pelo labor no processo de vida".

Já o trabalho seria "a atividade correspondente ao artificialismo da vida humana, existência esta não necessariamente contida no eterno ciclo vital da espécie, e cuja mortalidade não é compensada por este último" (ibidem). Tratase aqui, evidentemente, da tradicional definição de trabalho como intervenção do homem sobre a natureza. Finalmente, a ação seria, para Arendt, "a única atividade que se exerce entre os homens sem a mediação das coisas ou da matéria, correspondendo à pluralidade, ao fato de que homens e não o Homem , vivem na Terra e habitam o mundo". 
O estudo dessa autora ajuda a compreender como os processos metabólicos e orgânicos do corpo, o trabalho como cultura, ou ainda a "intervenção do homem sobre a natureza" e as ações estariam intrinsecamente associados e constituem aquilo que chamou de condição humana.

Ora, para entendermos se e em que medida o corpo pode ocupar um entrelugar entre a contemplação e a ação na educação e na arte, é preciso pensar o mais polêmico dos três conceitos da autora: o labor.

A aproximação e o distanciamento entre labor (de nosso corpo), o trabalho (de nossas mãos), condicionados pela categoria da ação (entre os iguais), por sua vez, constituem um sistema dinâmico que oscilaria entre vida ativa e vida contemplativa, uma importante contribuição para os estudos do corpo. No trecho da obra que discute o labor e a sociedade de consumidores, a autora afirma que "o artista seria o único trabalhador que teria restado numa sociedade de operários".

O uso do termo "operários" requer que se destaque que, segundo a autora, a maioria dos homens teria sido reduzida à condição de animales laborantes, que são guiados e não guiam, que fabricam e não agem, como consumidores vorazes. Ainda que esta ideia não seja nova e tenha sido exaustivamente investigada pela Escola de Frankfurt, ela foi pouco explorada nos estudos do corpo.

$\mathrm{O}$ que a autora pretende, com essa consideração e com sua conclusão de que o animal laborans teria vencido a batalha contra o homo faber, é alertar para a quase impossibilidade da "ação", aquilo que ela teria conceituado como o que ocorre entre os homens sem a mediação da matéria: "Os ideais do homo faber, fabricante do mundo, que são a permanência, a estabilidade e a durabilidade, foram sacrificados em benefício da abundância, que é o ideal do animal laborans". (Arendt, 2008, p. 138).

Suas considerações são de enorme importância para o professor e o artista, já que, numa sociedade de operários convertidos em animales laborantes, todos se voltam para a fabricação e para o consumo, sendo preciso, então, justificar o papel de ambos; ou pensar como seriam possíveis a educação e a arte num mundo com dificuldades de pensar e refletir.

Ao mesmo tempo, a insurreição do eu-corpo pode ser vista como revolta do corpo contra os séculos de domínio do cérebro, o que levaria à conclusão de ter-se passado de um extremo (pensamento e reflexão, uso do cérebro) a outro (atividade, aqui no sentido de uso do corpo, ação corporal desprovida de reflexão ou pensamento, de descolamento entre corpo e alma).

Não é difícil associar o pensamento pessimista de Arendt, de vitória do animal laborans sobre o homo faber à arte e à resistência política no século XX, por exemplo, por meio do personagem imortalizado por Charlie Chaplin, 
Carlitos, em Tempos modernos ${ }^{2}$. Considerado o século XX como palco de acontecimentos e transformações, essa fase do aumento do controle do tempo e dos movimentos do corpo do trabalhador, discutida de forma brilhante por autores como Braverman, coincidiu com experiências estéticas que envolvem a Biomecânica de Meyerhold, no teatro, e os experimentos da Bauhaus, como o Balé Triádico, de Oskar Schlemmer, na República de Weimar, os quais incorporaram no seu fazer artístico os desafios estéticos e éticos que envolveram a forjadura do homem-máquina do século XX; mas que, sobretudo, pressionaram a arte e os artistas a construírem o seu próprio discurso perante a emergência desse soldado do industrialismo.

Ainda sobre as teorias do trabalho a respeito do corpo, e particularmente no que diz respeito à mão humana, cabe introduzir a contribuição de Fischer (1987, p. 12-20) na sua obra $A$ necessidade da arte. Trata-se de um autor que reconhece que, para ser artista, o homem precisa "controlar e transformar a experiência”. Ele demonstra o quanto a porção homo faber de cada um precisa ser despertada, ressaltando que a arte é uma forma de trabalho: "A arte é quase tão antiga quanto o homem. É uma forma de trabalho e o trabalho é uma atividade característica do homem”. (Fischer, 1987, p. 21).

Ao afirmar que "a mão é uma descobridora há mais tempo do que o cérebro" (p. 29), este autor indica pistas da indissolubilidade entre arte e trabalho e fornece munição teórica e epistemológica à educação e à arte perante a hegemonia da medicina e da biologia sobre os estudos do corpo. Fischer também recorre a Thomas de Aquino, bem como a Marx, este duramente criticado por Arendt, destacando que "o pensamento não passa de uma forma de experimentação da experiência” (Fischer, 1987, p. 27). Esta simples afirmação do autor permitenos colocar em questão a hegemonia do verbo e da palavra sobre a carne ao longo do século XX, levando-nos a questionar por que a experiência, que se traduziria pela experimentação na forma de pensamento — o que não a limita aos experimentos do laboratório das ciências duras —, desapareceu do espaço da escola e da universidade.

É compreensível que, de certa forma, Fischer esteja em conflito com Arendt, a qual relaciona a ação à palavra, ao pensamento e à reflexão, "entre homens sem a mediação da matéria", embora, por outro lado, o autor dialogue com Walter Benjamin, que, por exemplo, em Magia e técnica, arte e politica, no capítulo em que discute o Narrador de Leskov, destaca a importância da relação entre a alma, o olho e a mão.

2. Para acessar uma célebre cena do personagem em ação no filme: < http://www.youtube.com/ watch? $v=$ ljarLbD9r30 $>$. Consulta em janeiro de 2010. 
Na obra dos dois, Fischer e Benjamin, a mão possuiria um papel de destaque na produção do conhecimento e do saber, embora não um saber regido exclusivamente pelo cérebro.

Ao relacionar a prática do artista à alma, ao olho e à mão, Benjamin (1994, p. 221) destaca que "o narrador é a figura na qual o justo se encontra consigo mesmo". Há ali um apelo ético, em cujo centro estão o trabalho e a relevância social do artista narrador, ele mesmo um trabalhador social.

Seria, portanto, a mão, em sintonia com o olho e a alma, que realizaria o trabalho do homo faber. Em Benjamin, portanto, o homo faber que, segundo Arendt, teria sido vencido pelo animal laborans, recupera o seu lugar de protagonista da condição humana, o que obriga a pensar esta categoria como um conceito amplo e não circunscrito a relações de produção no campo econômico e de embate entre capital e trabalho. Da mesma forma, pensar a união ou a amálgama entre o homo faber de Arendt e Fischer e o justo de Benjamin não pode traduzir-se pela figura de um mero construtor ou forjador de coisas, mas, sim, por alguém que prolonga a idade do mundo, mantendo a memória por meio de suas obras, dos instrumentos que constroem outros instrumentos.

Não há como não introduzir nesta relação tensa entre o animal laborans e o homo faber; entre o olho, a mão e a alma, a ruptura ocorrida nas sociedades ditas ocidentais entre arte e artesanato e também entre teoria e prática. Ao recorrer a autores que estabeleceram contato com o Oriente, passando de Artaud e Brecht a Peter Brook e Eugênio Barba, constata-se algo de elo perdido, de ruptura entre teoria e prática, e é claro que, neste momento, é preciso pensar a arte como área de conhecimento; portanto, sujeita aos encarceramentos como aquele do papel A-4 já apontado no começo deste texto.

No contexto das relaçôes entre arte e cultura, pode-se afirmar que o trabalho interfere, aumentando a "durabilidade" do mundo na forma das obras de arte, por exemplo, sobrevivendo, assim, ao tempo ditado pelo ciclo da natureza e resistindo à voracidade imposta pelo labor do corpo. A própria duração do mundo é, em certa medida, fruto desta outra porção do homem, que chamo, baseado na autora citada, de homo faber.

Mas, contraditoriamente, a fragmentação do corpo ganhou um enorme impulso quando a sociedade do trabalho do século XX, que de alguma maneira foi inspirada pelo sujeito iluminista, começou a declinar e cedeu espaço para a sociedadelaboratório.

\section{Aspectos conclusivos}

Neste texto, procurei discutir o corpo, num primeiro momento, elencando diferentes significados atribuídos a este conceito e destacando o esforço de 
alguns teóricos que se dedicaram a construir uma retrospectiva sobre ele, notadamente a partir de um referencial teórico e histórico.

$\mathrm{Na}$ discussão, busquei situar o corpo num entrelugar que respondesse às inquietaçôes tanto dos que pensam e refletem sobre ele, recriando-o como objeto, como daqueles que, por meio da produção e da criação artística (dimensão estética) ou ainda do trabalho, fundem-se com ele num fazer e/ou ser. Trata-se aí, sobretudo, de uma alternativa à tradicional definição e instrumentalização do corpo por algumas disciplinas científicas que detêm papel hegemônico na tematização do corpo.

Posteriormente, procurei destacar as contribuições dos estudos no campo do trabalho, particularmente a partir da obra de Hannah Arendt. Nesse âmbito, ressaltei o impacto dos conceitos de trabalho, ação e, sobretudo, labor, para os estudos do corpo e suas consequências, mas também apresentei alguns questionamentos sobre a vitória do animal laborans sobre o homo faber.

A premissa ou o advento do observador livre de Einstein, vista por Arendt com perplexidade na obra Entre o passado e o futuro, corresponde ao que chamei de entrelugar, neste texto, que penso poder ser ocupado pelo artista e pelo professor. Este entrelugar - de ser e ter um corpo, de encontro da estética e da ética - é também um entrelugar ocupado pelo homem ou pela humanidade que, ao ter abandonado o seu habitat (Planeta Terra) com as mãos da tecnologia, criou formas de sustentar a existência da espécie fora do lugar para o qual esta vida humana teria sido concebida, criando, com isso, uma força simbólica e real que impactou de maneira direta a forma de pensar o corpo, na ciência e na arte. Proponho ser possível pensar o corpo e o sujeito ou indivíduo postado no espaço, exatamente como o observador livre de Einstein, e, assim, pensar a ação humana em áreas como a educação e a arte de forma inventiva e inovadora, com uma espécie de multiolhar. Vejo e sinto o meu corpo de dentro dele, com meus pés sobre o planeta (oikia) e também sou um exilado, um astronauta, um humanoide na diáspora do universo, postado no espaço sideral, observando a vida e o mundo que eu criei.

A miniaturização, a nanonização, e a separação dos processos corporais, que aumentaram a sua subdivisão, por sua vez aumentando ou mudando radicalmente o limiar de controle do indivíduo sobre o corpo, geraram e gerarão consequências para a arte, a educação e a ciência, ainda não plenamente conhecidas. Trata-se aí claramente de uma vitória do homo faber, e não do animal laborans. Mas o entrelugar que proponho também permite lembrar que não há vencedor nessa batalha, pois o labor de nosso corpo e o trabalho de nossas mãos estão em eterno conflito e eterna colaboração dentro de nós e no mundo que criamos pelo trabalho e por suas ramificações, a educação, a arte e a ciência.

Ao propor que a emergência do observador livre de Einstein possa ser algo 
positivo para os que trabalham com a construção do conhecimento, busco destacar em que medida o trabalho do cidadáo-artista numa sociedade laboratório pode ser profícuo e baseado na ideia de liberdade. Uma liberdade de observar os fenômenos e pensar com outros homens sobre os desafios relacionados à produção do conhecimento a partir dessa perspectiva de um transespaço e um transtempo corporal.

Ao tomar como ponto de partida a luta pela reunião ou pela manutenção dessa unidade, integridade e organicidade corporal para caracterizar ou abordar o conceito de corpo, defendo a ideia de que corpo e mente são ou representam o mesmo construto, ou seja: um conjunto de relações que permite compreender, de forma propositiva, que o corpo, comportando essa multiplicidade na unidade, situar-se-ia num entrelugar, não mais aquele ocupado pelo sujeito iluminista num mundo newtoniano, causal e verossimilhante.

Ao situar o trabalho do artista e do professor num entrelugar que, de alguma maneira, corresponde ao do observador livre de Einstein (o que vê o mesmo objeto por/de dentro e por/de fora), também tentei destacar que a arte e a educação podem incorporar até mesmo as contribuições dos estudos do cérebro e da mente, sem descartar as valiosas contribuiçóes merleaupontianas da experiência pré-teórica, da ideia de ser, ter e pensar um corpo.

\section{Referências bibliográficas}

ARENDT, H. Entre o passado e o futuro. São Paulo: Perspectiva, 2007.

ARENDT, H. A condição humana. Rio de Janeiro: Forense Universitária, 2008.

BENJAMIN, W. Obras escolhidas II. Magia e técnica, arte e política. São Paulo: Brasiliense, 1994.

BRAVERMAN, H. Trabalho e capital monopolista: a degradação do trabalho no século XX. Rio de Janeiro: Zahar, 1980.

CORBIN, A.; COURTINE, J. J.; VIGARELLO, G. História do corpo. Petrópolis: Vozes, 2008.

ELIAS, N. A sociedade dos indivíduos. Rio de Janeiro: Jorge Zahar, 1994.

FISCHER, E. A necessidade da arte. Rio de Janeiro: Guanabara, 1987.

FISCHER-LICHTE, E. (Hrg.) Körper Inszerierungen. Präsenz und kultureller Wandel. Tübingen: Attempto, 2000.

GHIRALDELLI JR, P. O corpo. Filosofia e educação. São Paulo: Ática, 2007.

GLEISE, J. A carne e o verbo. In: SOARES, Carmen. Pesquisas sobre o corpo. Campinas: Autores Associados, 2007. p. 1-21. 
GREINER, C. O corpo. São Paulo: Ana Blume, 2005.

MATTHEWS E. Mente. Conceitos-chave em filosofia. Porto Alegre: Artmed, 2007.

MERLEAU-PONTY, M. A estrutura do comportamento. São Paulo: Martins Fontes, 2006a.

MERLEAU-PONTY, M. A fenomenologia da percepção. São Paulo: Martins Fontes, 2006b.

MOULIN, A. M. O corpo diante da medicina. In: CORBIN, A.; COURTINE, J. J.; VIGARELLO, G. História do corpo. Petrópolis: Vozes, 2008. p. 15-82

Recebido em 10 de março de 2010 e aprovado em 11 de maio de 2010. 